\title{
BMJ Open Does a strategy to promote shared decision-making reduce medical practice variation in the choice of either single or double embryo transfer after in vitro fertilisation? A secondary analysis of a randomised controlled trial
}

Anne E M Brabers, ${ }^{1}$ Liset van Dijk, ${ }^{1}$ Peter P Groenewegen, ${ }^{1,2,3}$ Arno $M$ van Peperstraten, ${ }^{4}$ Judith $D$ de Jong ${ }^{1}$

To cite: Brabers AEM, van Dijk L, Groenewegen PP, et al. Does a strategy to promote shared decisionmaking reduce medical practice variation in the choice of either single or double embryo transfer after in vitro fertilisation? A secondary analysis of a randomised controlled trial. BMJ Open 2016;6:e010894. doi:10.1136/bmjopen-2015010894

- Prepublication history for this paper is available online. To view these files please visit the journal online (http://dx.doi.org/10.1136/ bmjopen-2015-010894).

Received 17 December 2015 Revised 29 March 2016 Accepted 5 April 2016

CrossMark

For numbered affiliations see end of article.

Correspondence to Anne E M Brabers; a.brabers@nivel.nl

\section{ABSTRACT}

Objectives: The hypothesis that shared decisionmaking (SDM) reduces medical practice variations is increasingly common, but no evidence is available. We aimed to elaborate further on this, and to perform a first exploratory analysis to examine this hypothesis. This analysis, based on a limited data set, examined how SDM is associated with variation in the choice of single embryo transfer (SET) or double embryo transfer (DET) after in vitro fertilisation (IVF). We examined variation between and within hospitals.

Design: A secondary analysis of a randomised controlled trial.

Setting: 5 hospitals in the Netherlands.

Participants: 222 couples (woman aged $<40$ years) on a waiting list for a first IVF cycle, who could choose between SET and DET (ie, $\geq 2$ embryos available).

Intervention: SDM via a multifaceted strategy aimed to empower couples in deciding how many embryos should be transferred. The strategy consisted of decision aid, support of IVF nurse and the offer of reimbursement for an extra treatment cycle. Control group received standard IVF care.

Outcome measure: Difference in variation due to SDM in the choice of SET or DET, both between and within hospitals.

Results: There was large variation in the choice of SET or DET between hospitals in the control group. Lower variation between hospitals was observed in the group with SDM. Within most hospitals, variation in the choice of SET or DET appeared to increase due to SDM. Variation particularly increased in hospitals where mainly DET was chosen in the control group.

Conclusions: Although based on a limited data set, our study gives a first insight that including patients' preferences through SDM results in less variation between hospitals, and indicates another pattern of variation within hospitals. Variation that results from patient preferences could be potentially named the

\section{Strengths and limitations of this study}

This study is the first to elaborate further on, and explore the association between shared decisionmaking (SDM) and medical practice variations.

- Data from a randomised controlled trial are used, which enables a comparison to be drawn between a situation with and one without SDM.

- A limitation is that we had only access to a limited data set, and that we performed descriptive statistics to test our hypotheses.

informed patient rate. Our results provide the starting point for further research.

Trial registration number: NCT00315029; Post-results.

\section{INTRODUCTION}

Considerable variation exists in medical treatment. ${ }^{1-4}$ In a paternalistic model, the physician is the dominant actor deciding on this treatment. ${ }^{5} 6$ This approach is widely practiced and is embedded in the idea that physicians decide on treatment based on medical science and what is best for an individual patient, ${ }^{3}$ that is, the belief 'the doctor knows best'. As such, physicians' professional judgements rather than patients' preferences often determine which treatment a patient receives (ref. 3, p.9). ${ }^{7}$ As a result, medical practice variation is found to be related to physicians rather than to patients. ${ }^{389}$ In explaining this variation research, therefore, focuses on the role of physicians and the patients' influence receives little attention. ${ }^{10}{ }^{11}$ Research showed 
that variation, among others, can be explained by differences in opinions on or enthusiasm for certain procedures between individual physicians, and by differences in constraints and social influences on groups of physicians, for example, between hospitals. ${ }^{9}{ }^{11-14}$ In the past decades, however, the paternalistic model has been questioned. Also, the position of patients in healthcare has significantly altered. On an individual level, they are supposed to take up an active role in their health, ${ }^{15}$ and are expected to be involved in decisions about their health. ${ }^{16}$ There is, thus, an increased emphasis on including patients and their preferences in medical decision-making. ${ }^{17}{ }^{18}$ Since medical decision-making is decisive for variation in medical practice, it is questioned whether patients can still be ignored in theories about variation. Providing care that is respectful of, and responsive to an individual patient's preferences, so-called patient-centredness, is regarded as being of primary importance to healthcare alongside dimensions such as being safe, effective, timely, efficient and equitable. ${ }^{19}$

Medical decisions regarding treatment may change through the inclusion of patients' preferences as these preferences may deviate from physicians' professional judgements. ${ }^{20}$ Including patients' preferences may result in different treatment choices, and patterns of variation. It has been hypothesised that patients' involvement may reduce variation in medical practice because research shows that patients, through a combination of education and participation, were less ready to accept certain procedures. ${ }^{21}$ This also assumes that physicians are more diverse in their preferences than patients despite the fact that they have a shared training and socialisation that has no parallel among patients. ${ }^{21}$ One specific approach to patient involvement is shared decisionmaking (SDM) ${ }^{22}{ }^{23} \mathrm{SDM}$ is especially important in case of preference sensitive care, that is, when there is more than one clinically appropriate treatment option. SDM is defined as an approach where physicians and patients take decisions together using the best available evidence. Patients are helped to make informed choices by considering the options, and the likely benefits and disadvantages of each option. ${ }^{24} 25$ This is important as informed patients often prefer other treatments than those chosen by their physician. ${ }^{3}$ Research shows that, in general, informed patients prefer less invasive treatment options. ${ }^{326}$ For example, a study of Deyo et $a l^{27}$ showed that patients with herniated disks who watched a video programme chose less surgery. On the other hand, variation exists between physicians, since some of them prefer invasive treatments and others conservative treatments. ${ }^{28}$ As such, it has been suggested that SDM-as a case of patient involvement-reduces medical treatment variation. ${ }^{23}{ }^{29-31}$ However, no clear evidence about the association between SDM and medical practice variation is available as yet. ${ }^{11}$ There is no research which has identified exactly how or why SDM might reduce this variation. Therefore, this study further elaborates on the mechanisms that may explain why SDM reduces medical practice variation. In addition, we aim to perform a first explorative analysis on a limited data set to examine the hypothesis that SDM reduces medical practice variation. Here we make use of a clear example of a decision which depends on patients' preferences, the choice of either a single embryo transfer (SET) or double embryo transfer (DET) after in vitro fertilisation (IVF). ${ }^{32}$

SET prevents a multiple pregnancy with associated higher risks. DET results in higher live birth rates per treatment cycle $^{33} 34$ (see box 1 for more information). The percentage of SET varies considerably between countries. ${ }^{35-37}$ For example, rates of SET ranged from $8.7 \%$ in Moldova to $70.7 \%$ in Sweden. ${ }^{37}$ Likewise, major differences exist in how this complex decision is taken. These differences exist between countries, and between hospitals within the same country. In some hospitals, the decision is based solely on clinical parameters, while in other hospitals the patients are fully involved in the decision and physicians act as their advisor. ${ }^{38}$ If the physician decides on SET or DET, this decision is mainly based on the physicians' professional judgements. As such, decision variation is likely. When patients are involved, decisions may differ; informed patients often prefer less invasive treatments. ${ }^{3} 26$ The data from the randomised controlled trial (RCT) analysed in this study, in which a strategy for SDM was used as intervention, showed that educated couples, who understood the risks of twin pregnancies, were more inclined to choose SET; this is as compared with couples receiving standard care. ${ }^{32}$

We examine how a strategy to promote SDM is associated with variation in choosing SET or DET both between and within hospitals. We hypothesise that SDM is associated with less variation between hospitals since we expect that, due to SDM, SET is chosen more often both in hospitals where physicians already preferred SET and in hospitals where physicians preferred DET as educated couples prefer this (H1). We also hypothesise

Box 1 The choice of single embryo transfer (SET) or double embryo transfer (DET): a complex decision-making problem

The choice of a SET or DET after in vitro fertilisation (IVF) is a complex decision-making problem because of the need to find a balance between the risk of complications of multiple birth and the best chance of pregnancy. ${ }^{32}$ Some subfertile couples and professionals regard twin pregnancies as a success; however, this could also be considered as a side effect or even a complication. ${ }^{45}$ Twin pregnancies are associated with higher morbidity and mortality rates for mother and child compared with singleton pregnancies. $^{34}$ Moreover, complications of twin pregnancies cause substantial use of medical budgets. ${ }^{46}{ }^{47}$ Subsequently, twin pregnancies are increasingly regarded as undesirable. To prevent twin pregnancies, professionals and couples could choose SET instead of DET. ${ }^{34}{ }^{45}$ However, this may be disadvantageous since it could result in a lower pregnancy rate per IVF cycle. ${ }^{33}$ The choice of SET or DET is ideally decided through shared decision-making. ${ }^{48}$ 
that if DET is mainly preferred within a hospital and there is thus hardly any variation, then SDM is expected to increase variation because SET will be chosen more often due to SDM (H2). Whereas, if SET is mainly preferred within a hospital and there is thus hardly any variation, then SDM is expected not to change variation since SET is still preferred due to SDM (H3). Furthermore, we hypothesise that if DET and SET are both chosen within a hospital and there is thus large variation, SDM is expected to decrease variation because, due to SDM, SET is likely to be chosen more often than DET (H4).

\section{METHODS}

\section{Description of the data}

Data for this research were obtained from the RCT by van Peperstraten et al. ${ }^{32}$ The choice for SET or DET should ideally be decided in a SDM process by an educated and empowered couple. In the RCT study of van Peperstraten et $a l,{ }^{32}$ a multifaceted strategy was used to promote SDM. To promote SDM, van Peperstraten et al developed a decision aid (DA; see box 2 for more information). DAs are standardised evidence-based tools intended to promote SDM. ${ }^{23}$ Besides the evidence-based DA, this strategy consisted of the support of an IVF nurse, and reimbursement for an additional cycle of IVF for couples for whom the choice of SET caused a reduced chance of pregnancy. ${ }^{32}$ In the Netherlands, up to three IVF cycles are covered by the basic (but extensive) health insurance. The content of the DA and the reimbursement offer were discussed in person with a trained IVF nurse. All three elements of the strategy were provided before the counselling session that was part of standard care. ${ }^{32}$ The control group received standard IVF care, including a session discussing the choice of SET or DET. Next to this standard care, the intervention group received the multifaceted empowerment strategy. ${ }^{32}$ In the original RCT study, participating women completed three questionnaires (at inclusion,

Box 2 The choice of single or double embryo transfer: an evidence-based decision aid (DA)

van Peperstraten et $a^{\beta 2}$ developed and tested the evidence-based DA for deciding how many embryos to transfer during in vitro fertilisation. ${ }^{48}$ The DA was developed according to the checklist of the International Patient Decision Aids Standards Collaboration, which consists of 50 items divided between three domains, content, development and effectiveness. ${ }^{48} 49$ The purpose of the $\mathrm{DA}$ is to give couples all the information needed to make the choice to transfer one or two embryos, and to relate the information to their own personal situation. The DA consists of three chapters: (1) information about the chances of a single pregnancy or a twin pregnancy; (2) information about the risks of twin pregnancies; and (3) an explanation of the available options and an action plan. ${ }^{48}$ The DA is available in English at: http://www.umcn. nl/ivfda-en. after intervention (but before starting treatment), and 5 weeks after embryo transfer) to measure decisionmaking outcomes and knowledge. Results showed that the proportion of couples in the intervention group who wanted to decide for themselves on the number of embryos to be transferred increased, while this percentage remained the same in the control group $(\mathrm{p}<0.001)$. Levels of experienced knowledge $(p=0.001)$ and actual knowledge $(\mathrm{p}<0.001)$ were higher in the intervention group compared with the control group. ${ }^{32}$ For further detailed information, see van Peperstraten et al. ${ }^{32}$

Before the study, in 2005, 39\% of the couples underwent SET after the first cycle. ${ }^{39}$ The RCT was performed in five hospitals in the Netherlands. It included couples on the IVF waiting list between November 2006 and July 2007. The follow-up was continued until December 2008. Couples with women under 40 years of age were included if they were on the waiting list for their first IVF cycle ever or a first cycle after a previous successful IVF. Couples were excluded if SET was mandatory due to a strict medical indication. Written informed consent was provided by the couples before participation. ${ }^{32}$

\section{Selection of the data}

In total, 308 couples at the beginning of their first IVF cycle were included in the intention-to-treat (ITT) analysis of van Peperstraten et $a l^{32}$ In all five hospitals, approximately half of the couples received standard care, while the other half received the intervention. In this study, only couples who had the opportunity to choose between SET and DET were included. We, therefore, omitted from the 308 couples included in the ITT all the couples: (1) where the woman was pregnant before starting IVF ( $\mathrm{N}=20)$; (2) who had never started IVF $(\mathrm{N}=13)$ and (3) who had none or just one embryo available $(\mathrm{N}=39, \mathrm{~N}=14$, respectively). Our sample included 222 couples, 113 in the control group and 109 in the intervention group. The outcome measure used in this study was the choice of either SET or DET. The data on this outcome were collected by van Peperstraten $e t a l^{22}$ from local IVF registries. Other variables included were whether a couple was involved in the intervention or in the control groups, and the hospital in which a couple was treated. In addition, we included four variables that are of medical relevance and might, therefore, affect the choice of SET or DET, and thus in medical practice variation. For example, the older the woman is, the less likely she will become pregnant and the more likely she will have twins. The four variables included were: (1) the age of the woman (in years); (2) the duration of infertility (in years); (3) the presence of a good quality embryo (yes/no) and (4) any previous pregnancies (yes/no). Data on the presence of a good quality embryo were collected by van Peperstraten et $a l^{32}$ from local IVF registries. Data for the other three variables were collected through a patient questionnaire which couples received when included into the study. ${ }^{32}$ The woman's age and 
duration of infertility were calculated in this study on 31 December 2008 (=end of follow-up).

\section{Statistical analyses of the data}

We examined whether the control and intervention group were comparable for the characteristics included by performing descriptive statistics, and $\chi^{2}$ tests (categorical variables) and t tests (continuous variables; $\mathrm{p}<0.05$ ). We then examined whether the five hospitals included did significantly differ with respect to the four variables that are of medical relevance. If there were differences between the five hospitals then we had to take these into account through the rest of our analyses since these may have an impact on the choice of SET or DET. We performed descriptive statistics per hospital for the four variables. By $\chi^{2}$ tests (categorical variables) and one-way analyses of variance (ANOVA) (continuous variables), we tested if there were significant differences between the five hospitals for the woman's age, the duration of infertility, the presence of a good quality embryo and for previous pregnancies $(p<0.05)$. If a significant difference was found between the hospitals for one of the aforementioned variables, we then performed an additional analysis to examine if there was an association between that variable and the outcome measure.

We then calculated, for each hospital, the percentage of couples who chose SET or DET, both in the control and in the intervention groups. We examined this in order to confirm that educated couples are inclined to choose SET.

Next, we examined the variation between the hospitals. We first calculated for each hospital the percentage of SET in the control group, and then in the intervention group. Thereafter, we calculated the range of SET percentages for the control and the intervention groups. A smaller range or difference between the highest and the lowest percentage of SET implies less variation. Thus, if a strategy to promote SDM is associated with less variation between hospitals, then the range of SET percentages for the intervention group is smaller than that for the control group.

We now examined the variation within the hospitals by looking at the differences in variation between the control and the intervention groups in each hospital. We calculated for each hospital the absolute difference between SET and DET in the control as well as in the intervention groups. For example, if $40 \%$ chose SET and $60 \%$ DET, the absolute difference is 20 . There is no medical practice variation if the proportion of SET to DET is $0 \%$ compared with $100 \%$, or vice versa. Thus, there is no variation if the absolute difference is 100 . On the other hand, the most variation is observed if the proportion of SET to DET is $50 \%$ to $50 \%$. Thus, there is an absolute difference of 0 . We can thus create a scale ranging from 0 to 100 , where a score closer to 100 means less medical practice variation. We compared the scores of the control and the intervention groups for each hospital. If the score in a hospital is higher in the intervention group than in the control group, and thus closer to 100 (= no variation), then a strategy to promote SDM is associated with less variation within that hospital. Complementary to the descriptive statistics, we performed a multilevel analysis (MLA) in MLwiN to examine variation between hospitals. An MLA takes into account the nested structure of the data as well as the differences in the number of patients per hospital. All statistical analyses were carried out using STATA, V.13.1.

\section{RESULTS}

\section{Characteristics of the couples included}

A description of the 222 couples included is given in table 1 . The number of couples included ranged from 12 couples in hospital 5 to 153 couples in hospital 1 (see table 1). The control and intervention groups did not differ significantly with respect to the characteristics included. Furthermore, no significant differences were observed between the five hospitals for the mean duration of infertility $(p=0.256)$, the presence of a good quality embryo $(\mathrm{p}=0.406)$ and for previous pregnancies $(p=0.403$; see table 2$)$. ANOVA showed a significant difference $(p=0.032)$ for the variable, woman's age. An additional t test showed no difference between woman's age and the choice of SET or DET $(p=0.346)$. Thus, we decided not to include these four variables throughout the rest of the analyses.

\section{Choice of SET}

Table 3 shows the numbers and percentages of SET and DET for the control and intervention groups, in total and per hospital. In total, $52 \%$ of the couples included in the intervention group chose SET, in comparison with $39 \%$ of the couples in the control group ( $p=0.046$ ). To be more specific, in four of the five hospitals, couples in the intervention groups more often chose SET than DET. In hospital 4, however, couples in the intervention group more often chose DET than SET $(80 \%$ vs $20 \%)$. Although in hospital 4, couples in the intervention group more often chose DET, they more often chose SET $(20 \%)$ than couples in the control group $(0 \%)$.

\section{Variation between hospitals}

The range of SET in the control and intervention groups can also be observed in table 3 . The percentages of SET in the control groups ranged from $0 \%$ to $85.7 \%$, while the percentages of SET in the intervention groups ranged from $20.0 \%$ to $87.5 \%$. Therefore, the range of SET is smaller in the intervention group than in the control group, which is an indication that a strategy to promote SDM reduced variation in the choice of SET or DET between hospitals. The MLA also indicated that the variation between hospitals was lower in the intervention group than in the control group. However, the difference was not significant. 
Table 1 Characteristics of the couples included $(\mathrm{N}=222)$

\begin{tabular}{|c|c|c|c|c|}
\hline Characteristics & $\begin{array}{l}\text { Control group } \\
(\mathrm{N}=113)\end{array}$ & $\begin{array}{l}\text { Intervention group } \\
(\mathrm{N}=109)\end{array}$ & Total $(\mathrm{N}=\mathbf{2 2 2})$ & p Value* \\
\hline \multicolumn{5}{|l|}{ Hospital } \\
\hline Hospital 1 & 79 & 74 & 153 & NA \\
\hline Hospital 2 & 7 & 7 & 14 & \\
\hline Hospital 3 & 7 & 8 & 15 & \\
\hline Hospital 4 & 13 & 15 & 28 & \\
\hline Hospital 5 & 7 & 5 & 12 & \\
\hline Mean (SD) age of woman (years) $†$ & $\begin{array}{l}33.9(3.85) \\
\text { (range } 21-41 \text { years) }\end{array}$ & $\begin{array}{l}33.5(3.88) \\
\text { (range 25-41 years) }\end{array}$ & $\begin{array}{l}33.7(3.86) \\
\text { (range } 21-41 \text { years) }\end{array}$ & 0.475 \\
\hline Mean (SD) duration of infertility years) $\dagger$ & $\begin{array}{l}4.03(2.08) \text { (range } \\
1-13 \text { years) } \\
(\mathrm{N}=101)\end{array}$ & $\begin{array}{l}3.94(1.91) \text { (range } \\
1-12 \text { years) } \\
(\mathrm{N}=98)\end{array}$ & $\begin{array}{l}3.98(2.00) \text { (range } \\
1-13 \text { years) } \\
(\mathrm{N}=199)\end{array}$ & 0.749 \\
\hline \multicolumn{5}{|l|}{ Presence of a good quality embryo } \\
\hline No & 41 & 28 & 69 & 0.088 \\
\hline Yes & 72 & 81 & 153 & \\
\hline Previous pregnancies $\ddagger$ & $(\mathrm{N}=113)$ & $(\mathrm{N}=108)$ & $(\mathrm{N}=221)$ & \\
\hline No & 63 & 63 & 126 & 0.698 \\
\hline Yes & 50 & 45 & 95 & \\
\hline \multicolumn{5}{|c|}{$\begin{array}{l}\text { Values are numbers unless otherwise stated. } \\
\text { * } \mathrm{p}<0.05 \text { is significant. } \\
\text { †Calculated on } 31 \text { December } 2008 \text { based on information filled out in patients' questionnaires. As a result, we have a higher mean for age and } \\
\text { duration of infertility than van Peperstraten } \text { et al. } \\
\text { †Based on the question: 'Have you ever been pregnant?'. } \\
\text { NA, not applicable. }\end{array}$} \\
\hline
\end{tabular}

\section{Variation within hospitals}

Figure 1 shows the differences in variation within hospitals by illustrating, per hospital, the absolute difference between SET and DET in the control group (standard care) and the intervention group (strategy to promote SDM). In one hospital (hospital 2), the absolute difference in the control and the intervention groups is the same. This means that the variation within hospital 2 is the same with or without a strategy to promote SDM. Within hospital 3, the strategy to promote SDM appears to be associated with less variation, since the absolute difference in the control group is lower than in the intervention group (14 and 75 , respectively). On the other hand, within the other three hospitals, hospitals 1,4 and 5, the strategy to promote SDM appears to be associated with more variation. Within these three hospitals, the absolute difference in the control group is higher than that in the intervention group (see figure 1). Therefore, within some of the hospitals included, a strategy to promote SDM appears to be associated with more variation, while within other hospitals a strategy to promote SDM appears to be associated with less or the same level of variation.

\section{DISCUSSION AND CONCLUSIONS \\ Principal findings}

This study further elaborated on and explored the association between SDM and variation in the choice of SET or DET both between and within hospitals. There was large variation in the choice of SET or DET between hospitals in the control group. Lower variation between hospitals was observed in the group with a strategy to promote SDM. Furthermore, we observed that within most hospitals, the variation in the choice of SET or DET appeared to increase due to a strategy to promote SDM. This was particularly so in hospitals where mainly DET was chosen in the control group.

\section{What this study adds}

Literature suggests that SDM reduces variation. ${ }^{23}{ }^{29-31}$ To date, there is no clear evidence about this association. This study is the first that explored this association based on a case concerning the choice of SET or DET after IVF. We noticed that a strategy to promote SDM reduces variation between hospitals (confirming $\mathrm{H} 1$ ), while the variation within most hospitals appears to increase. The hypothesis in literature that SDM reduces variation is based on the observation that informed patients more often prefer less invasive treatments. ${ }^{3} 26$ We found that in most hospitals, couples in the intervention group more often chose SET. However, this does not imply that there will be less variation since our results indicate that variation within most hospitals increased. This is due to the fact that the level of variation without SDM differed between hospitals. For example, in some of the hospitals included mainly DET was preferred and there was, thus, almost no variation. Owing to the strategy to promote SDM, however, SET was chosen more often, and thus the variation increased within such hospitals, since now both SET and DET are chosen (confirming H2). In one hospital, SET was mainly chosen in the control group and we, therefore, 
Table 2 Characteristics of the couples included per hospital

\begin{tabular}{|c|c|c|}
\hline Characteristics & Total $(\mathrm{N}=222)$ & p Value* \\
\hline $\begin{array}{l}\text { Mean }(S D) \text { age of woman } \\
\text { (years) } \dagger\end{array}$ & $33.7(3.86)(21-41)$ & \\
\hline Hospital $1(\mathrm{~N}=153)$ & 33.8 (3.63) (21-41) & \\
\hline Hospital $2(\mathrm{~N}=14)$ & 30.9 (4.54) (25-39) & 0.032 \\
\hline Hospital 3 ( $\mathrm{N}=15)$ & $34.6(3.96)(28-40)$ & \\
\hline Hospital 4 ( $\mathrm{N}=28)$ & 33.4 (4.53) (25-41) & \\
\hline Hospital 5 (N=12) & $35.2(2.86)(30-38)$ & \\
\hline $\begin{array}{l}\text { Mean (SD) duration of } \\
\text { infertility (years) } \dagger\end{array}$ & $4.0(2.00)(1-13)$ & \\
\hline Hospital $1(\mathrm{~N}=139)$ & $4.1(2.20)(1-13)$ & 0.256 \\
\hline Hospital $2(\mathrm{~N}=11)$ & $4.0(1.26)(2-6)$ & \\
\hline Hospital $3(\mathrm{~N}=11)$ & 4.3 (1.85) (2-8) & \\
\hline Hospital $4(\mathrm{~N}=26)$ & $3.2(1.22)(1-6)$ & \\
\hline Hospital 5 ( $\mathrm{N}=12)$ & $4.0(1.13)(2-6)$ & \\
\hline $\begin{array}{l}\text { Presence of a good } \\
\text { quality embryo (\% yes) }\end{array}$ & $68.9 \%$ & \\
\hline Hospital $1(\mathrm{~N}=153)$ & $72.6 \%$ & 0.406 \\
\hline Hospital $2(\mathrm{~N}=14)$ & $64.3 \%$ & \\
\hline Hospital 3 ( $\mathrm{N}=15)$ & $66.7 \%$ & \\
\hline Hospital 4 ( $\mathrm{N}=28)$ & $60.7 \%$ & \\
\hline Hospital 5 ( $\mathrm{N}=12)$ & $50.0 \%$ & \\
\hline $\begin{array}{l}\text { Previous pregnancies } \ddagger \\
\text { (\% yes) }\end{array}$ & $43.0 \%$ & \\
\hline Hospital $1(\mathrm{~N}=153)$ & $45.8 \%$ & 0.403 \\
\hline Hospital $2(\mathrm{~N}=14)$ & $21.4 \%$ & \\
\hline Hospital $3(\mathrm{~N}=14)$ & $50.0 \%$ & \\
\hline Hospital 4 ( $\mathrm{N}=28)$ & $39.3 \%$ & \\
\hline Hospital 5 (N=12) & $33.3 \%$ & \\
\hline \multicolumn{3}{|c|}{$\begin{array}{l}{ }^{*} p<0.05 \text { is significant. } \\
\text { †Calculated on } 31 \text { December } 2008 \text { based on information filled out } \\
\text { in patients' questionnaires. As a result, we have a higher mean for } \\
\text { age and duration of infertility than van Peperstraten et al. }{ }^{32} \\
\ddagger \text { Based on the question: 'Have you ever been pregnant?'. }\end{array}$} \\
\hline
\end{tabular}

expected no change in variation since we expected SET was still preferred due to the strategy to promote SDM (H3). However, we observed an increase in variation in that hospital, rejecting H3. In the two hospitals with the largest variation in the control group, the variation decreased or remained equal, confirming H4. A subsequent implication is that an overall decrease in variation between hospitals provides no indication about the change in variation within an individual hospital. Although based on a limited data set, this study gives a first insight that SDM results in less variation between hospitals while suggesting another pattern of variation within hospitals.

\section{Further research}

This research focused on just one decision-making situation in obstetrics, and had only access to a limited data set. The results, therefore, have to be interpreted with caution and further research is necessary to underpin our results and examine questions that remain unanswered. Nevertheless, our study provides a starting
Table 3 The choice of single embryo transfer (SET) or double embryo transfer (DET) total group, and per hospital

\begin{tabular}{|c|c|c|c|}
\hline & Control group & Intervention group & p Value ${ }^{\star}$ \\
\hline \multicolumn{4}{|l|}{ Total } \\
\hline SET & 44 (38.9\%) & 57 (52.3\%) & \\
\hline DET & 69 (61.1\%) & $52(47.7 \%)$ & 0.046 \\
\hline \multicolumn{4}{|c|}{ Hospital 1} \\
\hline SET & 31 (39.2\%) & 40 (54.1\%) & 0.066 \\
\hline DET & $48(60.8 \%)$ & $34(46.0 \%)$ & \\
\hline \multicolumn{4}{|c|}{ Hospital 2} \\
\hline SET & $3(42.9 \%)$ & $4(57.1 \%)$ & 0.593 \\
\hline DET & $4(57.1 \%)$ & 3 (42.9\%) & \\
\hline \multicolumn{4}{|c|}{ Hospital 3} \\
\hline SET & $4(57.1 \%)$ & 7 (87.5\%) & 0.185 \\
\hline DET & 3 (42.9\%) & $1(12.5 \%)$ & \\
\hline \multicolumn{4}{|c|}{ Hospital 4} \\
\hline SET & $0(0.0 \%)$ & 3 (20.0\%) & 0.088 \\
\hline DET & 13 (100.0\%) & $12(80.0 \%)$ & \\
\hline \multicolumn{4}{|c|}{ Hospital 5} \\
\hline SET & 6 (85.7\%) & $3(60.0 \%)$ & 0.310 \\
\hline DET & 1 (14.3\%) & $2(40.0 \%)$ & \\
\hline
\end{tabular}

Values are numbers (\%) unless otherwise stated.

${ }^{*} p<0.05$ is significant.

point for further empirical research within this area. For many medical problems, no absolute best treatment option is available, and so there are significant trade-offs among the available options. ${ }^{40}{ }^{41}$ We expect, however, that our results apply generally to medical problems with no absolute best treatment option. Decisions concerning such problems are defined as preference sensitive, since they depend on considerations of the benefits, disadvantages and uncertainties of each treatment. For example, some patients will prefer to accept a small risk of death in order to attempt to improve their function, while others will not. ${ }^{23}{ }^{41}$ Therefore, the best decisions cannot be made without including patients' preferences. ${ }^{40}{ }^{41}$ Well-known examples include chronic back pain, early-stage breast cancer and prostate cancer. For examples such as these it is believed that variation will change as a result of SDM. Future research has to confirm this by making use of data from multicentre RCT studies that applied intervention strategies (like a DA) to increase SDM in a specific consultation. Such RCT studies have been carried out ${ }^{26}$ but have focused, comparable to the study we used, on outcome measures other than variation. Therefore, we decided in this study to perform a secondary analysis. Any possible multicentre studies should include a control and an intervention group which could thus measure actual treatment choices with and without SDM. This will allow researchers to examine whether SDM changes the pattern of variation by, for example, using the same method as we did. Another possibility for further research is to conduct a new multicentre RCT study specifically aimed at analysing the relationship between SDM and medical practice variation. 
Figure 1 Variation within hospitals. A measure of variation for the control and intervention groups per hospital. DET, double embryo transfer; SET, single embryo transfer.

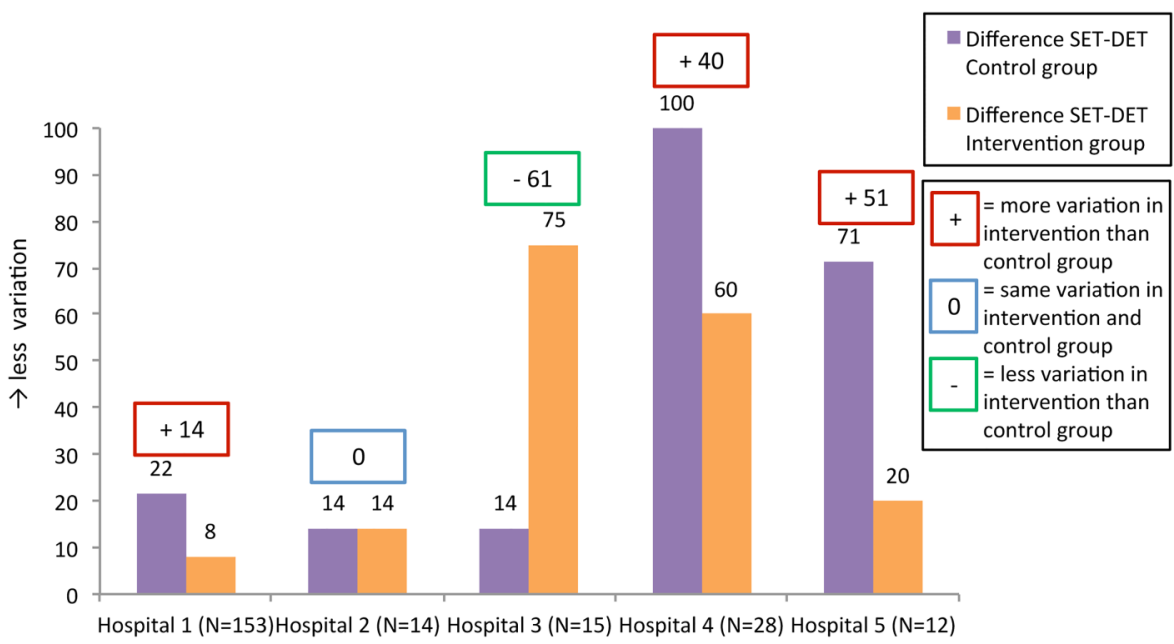

Our results show that a strategy to promote SDM results in less variation between hospitals and indicates another pattern of variation within hospitals, confirming our hypotheses. These results appear to show that the decisions made by informed patients have a pattern too. Choices made by informed patients appear to have a rate which deviates from baseline rates, irrespective of whether those are 'low' or 'high'. This could be potentially named the informed patient rate. However, it can be questioned whether the rates we observed are indeed the informed patient rate, that is, the results of what the couples want. It is possible that not all patients were able or preferred to take a shared decision about the choice of SET or DET. Nevertheless, results of the original RCT study show that levels of experienced knowledge $(\mathrm{p}=0.001)$ and actual knowledge $(\mathrm{p}<0.001)$ were higher in the intervention group compared with the control group. ${ }^{32}$ Further research has to examine whether the actual choice was indeed the patients' preference and whether there are differences between groups of patients for this. In addition, a different pattern of variation due to SDM might be a positive indication for the quality of care. Good healthcare requires, among others, providing care that is respectful of and responsive to individual patients' preferences. ${ }^{19}$ This is particularly true for preference sensitive decisions, since these decisions depend on patients' preferences regarding the benefits, disadvantages, and uncertainties of each treatment. Further research has to examine whether SDM results in better quality of care for preference-sensitive decisions.

The broad context of this study is about the influence of patients and their preferences on variation in medical practice. SDM is one option for including patients' preferences in medical decision-making. There are other options through which patients can express their preferences, and thus influence the pattern of variation. For example, patients differ in how much pressure they are able to put on physicians. ${ }^{13} 42$ They differ in their ability to take part in discussions over treatment with their physicians. Some patients are expected to be able to ask their physician for another treatment than, for example, the treatment that is recommended in a guideline or the one that is preferred by the physician. ${ }^{13}{ }^{43}$ If this is the case, then patients' preferences appear to influence the treatment chosen, and thus the variation. Further research is recommended regarding these situations.

\section{The strengths and weaknesses of the study}

A strength of our study is that we are the first to elaborate further on and explore the association between SDM and variation in medical treatment. We examined this association to get insight into whether including patients' preferences through a strategy to promote SDM results in another pattern of variation in medical treatment. Another strength is the use of data from a RCT. We had the opportunity to compare the variation in the choice of SET or DET with and without SDM. It might be possible that the choice of SET or DET in the control group is influenced by physicians, since they treated both couples in the intervention and in the control group. Ideally, data would have been available about the percentage of SET and DET before the RCT, allowing us to compare the intervention and control groups with these percentages. Though another study showed that in 2005, before the RCT, 39\% of twin-prone couples in two Dutch hospitals chose SET, ${ }^{39}$ which is comparable to the percentage of SET in the control group. It seems plausible to use the control group as the situation before SDM. We performed descriptive statistics to analyse our data because of the low numbers of couples included in the hospitals. We have taken into account the nested structure of the data by performing our analyses per hospital. However, we did not take into account the differences in the number of patients per hospital. We, therefore, also performed an MLA to examine the variation between hospitals. The MLA supported the results of the descriptive statistics; however, the difference was not significant. From the data set it was only known in which hospital a couple was treated, and not by which physician within that hospital. However, only one or two physicians per hospital treated all couples in that hospital; therefore, we do not expect 
that this will affect our conclusions. Further research should ideally be performed with a larger data set, preferably using MLA in order to test the hypothesis of this study. This would acknowledge that patients are nested hierarchically within physicians and physicians within hospitals. In addition, further research has to include into the analyses the sociodemographics that might have an influence on treatment decision. Another limitation might be that the original RCT did not assess whether more SDM actually took place. As such, it is unclear whether the strategy really led to more SDM. A final limitation might be that the intervention consisted of different elements, and thus it is difficult to assess separately the effects of these elements. Despite the fact that at the end of the follow-up period only $4 \%$ of the couples qualified for reimbursement of a fourth cycle, reimbursement might have played a role in the decision. ${ }^{32}$ However, a follow-up study showed that-compared with the other elements-the reimbursement offer was rated least important by the couples in choice for SET or DET. ${ }^{44}$

\section{CONCLUSIONS}

This study was the first to elaborate further on and explore the relationship between including patients' preferences in medical decision-making and practice variation. Although based on a limited data set, our study gives a first insight that including patients' preferences through SDM results in less medical practice variation between hospitals, and indicates another pattern of variation within hospitals. The variation that results from patient preferences could be potentially named the informed patient rate. The results of this study provide the starting point for further empirical research within this area.

\section{Author affiliations \\ ${ }^{1}$ NIVEL, the Netherlands Institute for Health Services Research, Utrecht, The Netherlands \\ 2Department of Sociology, Utrecht University, Utrecht, The Netherlands \\ ${ }^{3}$ Department of Human Geography, Utrecht University, Utrecht, The Netherlands \\ ${ }^{4}$ Department of Obstetrics and Gynaecology, Radboud University Medical Center, Nijmegen, The Netherlands}

Acknowledgements The authors thank Peter Spreeuwenberg (NIVEL) for advising on and performing the MLA.

Contributors AEMB was involved in the design of the study, performed the statistical analyses and drafted the manuscript. JDdJ and LvD were involved in the design of the study, assisted in interpreting the results, assisted in drafting the manuscript and revised the manuscript. PPG was involved in the design of the study and revised the manuscript. AMvP was the primary author of the original RCT and was, therefore, responsible for the data collection, and revised the manuscript. All authors have read and approved the final manuscript.

Funding The RCT study was funded by the Netherlands Organisation for Health Research and Development (grant no 945-16-105). For this secondary analysis of the RCT no additional funding was obtained.

Competing interests All authors have completed the unified competing interest form at http://www.icmje.org/coi_disclosure.pdf (available on request from the corresponding author) and declare LvD received unrestricted grants from Bristol-Myers Squibb, Pfizer and Astra Zeneca for studies not related to this study.

Ethics approval The RCT study was approved by the regional ethics committee for medical research.

Provenance and peer review Not commissioned; externally peer reviewed.

Data sharing statement The data set of the RCT study is available on request from AMvP.

Open Access This is an Open Access article distributed in accordance with the Creative Commons Attribution Non Commercial (CC BY-NC 4.0) license, which permits others to distribute, remix, adapt, build upon this work noncommercially, and license their derivative works on different terms, provided the original work is properly cited and the use is non-commercial. See: http:// creativecommons.org/licenses/by-nc/4.0/

\section{REFERENCES}

1. Paul-Shaheen P, Clark JD, Williams D. Small area analysis: a review and analysis of the North American literature. J Health Polit Policy Law 1987;12:741-809.

2. Wennberg JE. Understanding geographic variations in health care delivery. N Engl J Med 1999;340:52-3.

3. Wennberg JE. Tracking medicine: a researcher's quest to understand health care. Oxford University Press, 2010.

4. Corallo AN, Croxford R, Goodman DC, et al. A systematic review of medical practice variation in OECD countries. Health Policy 2014:114:5-14.

5. Emanuel EJ, Emanuel LL. Four models of the physician-patient relationship. JAMA 1992;267:2221-6.

6. Charles C, Gafni A, Whelan T. Shared decision-making in the medical encounter: what does it mean? (or it takes at least two to tango). Soc Sci Med 1997;44:681-92.

7. Wennberg JE. Unwarranted variations in healthcare delivery: implications for academic medical centres. BMJ 2002;325:961.

8. McPherson K. Why do variations occur? In: Andersen TF, Mooney $\mathrm{G}$, eds. The challenges of medical practice variations. London: The Macmillan Press, 1990:16-35.

9. Wennberg JE, Gittelsohn A. Health care delivery in Maine I: patterns of use of common surgical procedures. J Maine Med Assoc 1975;66:123-30, 149.

10. Mercuri M, Gafni A. Medical practice variations: what the literature tells us (or does not) about what are warranted and unwarranted variations. J Eval Clin Pract 2011:17:671-7.

11. De Jong JD, Groenewegen PP, Westert GP. Sociological model for understanding medical practice variations. In: Sobolev B, (Series ed) Johnson A, Stukel T, eds. Health services research series medical practice variations. New York: Springer, 2015:1-15.

12. Chassin MR. Explaining geographic variations. The enthusiasm hypothesis. Med Care 1993;31(5 Suppl):Ys37-44.

13. De Jong JD. Explaining medical practice variation. Social organization and institutional mechanisms. NIVEL, 2008.

14. Westert GP, Groenewegen PP. Medical practice variations: changing the theoretical approach. Scand J Public Health 1999;27:173-80.

15. van de Bovenkamp HM, Trappenburg MJ, Grit KJ. Patient participation in collective healthcare decision making: the Dutch model. Health Expect 2010;13:73-85.

16. Guadagnoli E, Ward P. Patient participation in decision-making Soc Sci Med 1998;47:329-39.

17. Frosch DL, Kaplan RM. Shared decision making in clinical medicine: past research and future directions. Am J Prev Med 1999;17:285-94.

18. Fraenkel L. Incorporating patients' preferences into medical decision making. Med Care Res Rev 2013;70(1 Suppl):80s-93s.

19. Institute of Medicine. Crossing the quality chasm: a new health system for the 21st century. National Academies Press, 2001.

20. Wennberg JE. Variation in use of Medicare services among regions and selected academic medical centers: is more better? Commonwealth Fund, 2005.

21. Greer AL, Goodwin JS, Freeman JL, et al. Bringing the patient back in. Guidelines, practice variations, and the social context of medical practice. Int J Technol Assess Health Care 2002;18:747-61.

22. Charles C, Gafni A, Whelan T. Decision-making in the physician-patient encounter: revisiting the shared treatment decision-making model. Soc Sci Med 1999;49:651-61.

23. O'Connor AM, Llewellyn-Thomas HA, Flood AB. Modifying unwarranted variations in health care: shared decision making using 
patient decision aids. Health Aff (Millwood) 2004;SupplVariation: VAR63-72.

24. Elwyn G, Frosch D, Thomson R, et al. Shared decision making: a model for clinical practice. J Gen Intern Med 2012;27:1361-7.

25. Elwyn G, Laitner S, Coulter A, et al. Implementing shared decision making in the NHS. BMJ 2010;341:c5146.

26. Stacey D, Bennett CL, Barry MJ, et al. Decision aids for people facing health treatment or screening decisions. Cochrane Database Syst Rev 2011(10):Cd001431.

27. Deyo RA, Cherkin DC, Weinstein J, et al. Involving patients in clinical decisions: impact of an interactive video program on use of back surgery. Med Care 2000;38:959-69.

28. McClure W. Toward development and application of a qualitative theory of hospital utilization. Inquiry 1982;19:117-35.

29. O'Connor AM, Wennberg JE, Legare F, et al. Toward the 'tipping point': decision aids and informed patient choice. Health Aff (Millwood) 2007;26:716-25.

30. Stiggelbout AM, Van der Weijden T, De Wit MP, et al. Shared decision making: really putting patients at the centre of healthcare. BMJ 2012;344:e256.

31. Weinstein JN, Bronner KK, Morgan TS, et al. Trends and geographic variations in major surgery for degenerative diseases of the hip, knee, and spine. Health Aff (Millwood) 2004;Suppl Variation: Var81-9.

32. van Peperstraten A, Nelen W, Grol R, et al. The effect of a multifaceted empowerment strategy on decision making about the number of embryos transferred in in vitro fertilisation: randomised controlled trial. BMJ 2010;341:c2501.

33. Pandian Z, Marjoribanks J, Ozturk O, et al. Number of embryos for transfer following in vitro fertilisation or intra-cytoplasmic sperm injection. Cochrane Database Syst Rev 2013;7:Cd003416.

34. Pinborg A. IVF/ICSI twin pregnancies: risks and prevention. Hum Reprod Update 2005;11:575-93.

35. Andersen AN, Goossens V, Ferraretti AP et al. Assisted reproductive technology in Europe, 2004: results generated from European registers by ESHRE. Hum Reprod 2008;23:756-71.

36. de Mouzon J, Goossens V, Bhattacharya S, et al. Assisted reproductive technology in Europe, 2006: results generated from European registers by ESHRE. Hum Reprod 2010;25:1851-62.
37. Ferraretti AP, Goossens V, Kupka M, et al. Assisted reproductive technology in Europe, 2009: results generated from European registers by ESHRE. Hum Reprod 2013;28:2318-31.

38. van Peperstraten A. Implementation of single embryo transfer: a patient directed strategy. Radboud Universiteit Nijmegen, 2009.

39. Van Peperstraten AM, Kreuwel IA, Hermens RP, et al. Determinants of the choice for single or double embryo transfer in twin prone couples. Acta Obstet Gynecol Scand 2008;87:226-31.

40. Barry MJ. Shared decision making: informing and involving patients to do the right thing in health care. $J$ Ambul Care Manage 2012;35:90-8.

41. Dartmouth Atlas. A Dartmouth Atlas project topic brief preference-sensitive care. Lebanon: The Dartmouth Atlas of Health Care, 2007.

42. Westert GP, Groenewegen PP, Lindenberg SM. De invloed van ziekenhuispatiënten op de duur van de hospitalisatie. TSG 1991;69:184-94.

43. Hajjaj FM, Salek MS, Basra MK, et al. Non-clinical influences on clinical decision-making: a major challenge to evidence-based practice. J R Soc Med 2010;103:178-87.

44. Kreuwel IA, van Peperstraten AM, Hulscher ME, et al. Evaluation of an effective multifaceted implementation strategy for elective single-embryo transfer after in vitro fertilization. Hum Reprod 2013;28:336-42.

45. [No authors listed]. Prevention of twin pregnancies after IVF/ICSI by single embryo transfer. ESHRE Campus Course Report. Hum Reprod 2001;16:790-800.

46. Wolner-Hanssen $\mathrm{P}$, Rydhstroem $\mathrm{H}$. Cost-effectiveness analysis of in-vitro fertilization: estimated costs per successful pregnancy after transfer of one or two embryos. Hum Reprod 1998;13:88-94.

47. Lukassen HG, Schönbeck Y, Adang EM, et al. Cost analysis of singleton versus twin pregnancies after in vitro fertilization. Fertil Steril 2004;81:1240-6.

48. van Peperstraten AM, Hermens RP, Nelen WL, et al. Deciding how many embryos to transfer after in vitro fertilisation: development and pilot test of a decision aid. Patient Educ Couns 2010;78:124-9.

49. Elwyn G, O'Connor A, Stacey D, et al. Developing a quality criteria framework for patient decision aids: online international Delphi consensus process. BMJ 2006;333:417. 